\title{
MODELO DE AVALIAÇÃO DE ARRANJOS FÍSICOS SOB A ÓTICA DA MANUFATURA CELULAR - MMCEL
}

\section{A MODEL FOR ASSESSING LAYOUTS FROM A CELLULAR MANUFACTURING PERSPECTIVE - MMCEL}

\author{
Giuliano Marodin ${ }^{1}$; Tarcísio Abreu Saurin ${ }^{2}$ \\ ${ }^{1}$ Escola de Administração (EA/UFRGS) e Programa de Pós-Graduação em Engenharia de Produção \\ (PPGEP/UFRGS) / Universidade Federal do Rio Grande do Sul - Porto Alegre - Brasil \\ zmarodin@terra.com.br \\ ${ }^{2}$ Programa de Pós-Graduação em Engenharia de Produção / Universidade Federal do Rio Grande do \\ Sul PPGEP / UFRGS - Porto Alegre - Brasil saurin@ufrgs.br
}

\begin{abstract}
Resumo
O objetivo deste artigo é propor um modelo de avaliação de arranjos físicos sob a ótica da manufatura celular (MC). Este artigo considera o fluxo das tarefas e de operadores conectados em relação aos elementos tempo, espaço e informação serem os princípios da MC. O modelo divide-se em quatro etapas: identificar a família de produtos; avaliar fatores críticos da MC; classificar o tipo de célula; e propor melhorias. Foram realizados dois estudos de caso a fim de avaliar a aplicabilidade do modelo, cujos resultados demonstram a rapidez e utilidade do modelo na avaliação e proposição de melhorias em células de manufatura.
\end{abstract}

Palavras-chave: manufatura celular; organização do trabalho; arranjo físico.

\section{Introdução}

A crescente utilização de células de manufatura durante a última década foi resultado principalmente da disseminação do Sistema Toyota de Produção. Inúmeras empresas ocidentais adotaram essa estratégia para competir em critérios como flexibilidade, tempo de resposta, custo e qualidade. Entretanto, tanto no meio acadêmico quanto nos ambientes organizacionais, ainda é freqüente observar a dificuldade de conceituação de células de manufatura, em particular no que diz respeito a sua diferenciação do arranjo físico celular (HYER; BROWN, 1999).

$\mathrm{Na}$ literatura, a definição mais usual de manufatura celular (MC) se refere a entender esta como apenas um arranjo físico, ou seja, um agrupamento de diferentes processos que permitam a produção de um conjunto de produtos similares (DROLET et al., 1996). Este conceito vem sendo criticado, dentre outros motivos, por focar apenas em dimensões técnicas, deixando de lado a dimensão humana (HYER et al., 1999). Segundo Wemmerlov e Johnson (1997) os fatores 
humanos, como envolvimento do empregado, liderança e rodízio, estão entre as variáveis menos discutidas em processos de implantação de células, embora possam ter um grande impacto em seus resultados.

A partir do reconhecimento da existência de diversos tipos de células de manufatura e da grande diversidade de resultados alcançados, Hyer e Brown (1999) enfatizam que esta forma de organização do trabalho contempla requisitos maiores que um simples arranjo físico. Na verdade, a interação entre os elementos tempo, espaço e informação seria responsável pelo desempenho da MC, influenciando nos principais benefícios trazidos por ela (HYER; BROWN, 1999). Estes elementos vêm sendo incorporados em trabalhos relativos a este tema no Brasil, como, por exemplo, em Santos et al. (2002) e Loiola et al. (2005). Entretanto, a literatura ainda não disponibilizou uma ferramenta que permita a caracterização de células de manufatura segundo os seus elementos essenciais, com intuito de melhorar o desempenho destas. Nesse contexto, este artigo pretende contribuir com um modelo de avaliação e identificação de melhorias em arranjos físicos sob a ótica da manufatura celular.

O modelo proposto, chamado de MMCel, possui quatro etapas. A primeira etapa identifica o arranjo físico com um arranjo celular baseado em tecnologia de grupo, essencial para a caracterização de uma célula de manufatura. A segunda etapa avalia o desempenho da célula de manufatura de acordo com os elementos tempo, espaço e informação. A intensidade e interação destes elementos são analisadas na terceira etapa, e, por fim, na etapa quatro são levantados os principais problemas vislumbrados e feitas às sugestões de melhorias.

O presente artigo esta dividido da seguinte forma, a Sessão 2 contêm os conceitos da MC, seguida da Sessão 3 que apresenta o método de pesquisa utilizado. O modelo proposto é apresentado na Sessão 4, e, após, estão descritos os dois estudos de caso onde o modelo foi aplicado, na Sessão 5. Finalmente, a Sessão 6 descreve as conclusões do trabalho.

\section{Manufatura Celular}

\subsection{Conceito}

O presente artigo adota a proposta de Wermmerlov e Johnson (1997), que conceituam a MC como uma forma de organização do trabalho. Deste modo, a MC não está limitada ao planejamento do arranjo físico, incluindo todo o planejamento do sistema sóciológico e técnico envolvido em seu funcionamento. Assim, a MC é composta por fatores técnicos, como, por exemplo, o agrupamento de processos e produtos, bem como em fatores sociais, como, por exemplo, os mecanismos de supervisão e grau de autonomia dos operadores (HYER et al., 1999). Hyer e Brown (1999) partiram do sistema técnico para desenvolver uma nova abordagem, afirmando que as células de manufatura 
devem possuir um fluxo de trabalho onde processos e operadores estejam intimamente conectados em relação aos elementos tempo, espaço e informação.

\subsection{Arranjo físico celular}

O arranjo físico celular é constituído pelo agrupamento de diferentes máquinas e equipamentos que permitam a produção de um conjunto de produtos similares em pequenos ou médios lotes (DROLET et al., 1996). Burbidge (1996) acrescenta que estes agrupamentos devem conter todos os recursos necessários para a fabricação do grupo de produtos produzidos. No agrupamento de produtos ao qual se refere o arranjo físico celular esta presente o conceito de Tecnologia de Grupo.

Enquanto um arranjo físico por processo está organizado para produzir em pequenos volumes e grande variedade, um arranjo físico por produto tem características contrárias, produzindo em grandes volumes e pequenas variedades. $\mathrm{O}$ arranjo físico celular está posicionado entre estes dois arranjos físicos, oferecendo a produção eficiente em volumes intermediários com uma variação considerável (HAYES; WHEELWRIGHT, 1979; SLACK et al., 2002). Vale também salientar que em muitas operações são utilizados arranjos físicos mistos, que são compostos de mais de um tipo de arranjo físico tradicional.

\subsection{Tecnologia de Grupo}

A tecnologia de grupo (TG), sob o aspecto da manufatura, é uma filosofia que busca obter vantagens econômicas e operacionais explorando as semelhanças mediante o estabelecimento de um grupo de similar de produtos (LORINI, 1993). O objetivo principal da TG na manufatura é redução da complexidade do fluxo produtivo, para que, através da redução em perdas na produção, possam ser obtidos ganhos de produtividade e flexibilidade (SILVEIRA, 1994). A TG é fundamental para arranjos celulares, pois, além de estar contida na definição deste arranjo físico que é resultado de um agrupamento, é responsável pelos benefícios ligados a três fatores principais, segundo Silveira (1994): redução de desperdícios ligados à troca de ferramental e ajustes em máquinas; racionalização do fluxo de materiais levando a redução de tempo de transporte e material em estoque; e diminuição da complexidade de sequenciamento de produção que pode resultar em maior velocidade e acurácia dos resultados de planejamento e controle de produção. Desta forma, os métodos de formação e avaliação de agrupamentos se tornaram fundamentais para $o$ desenvolvimento, a implantação e o funcionamento de células de manufatura. Em raros casos, como 
em Hyer et al. (1999), estas deciões aparecem como menos importantes para a implantação de células de manufatura.

Existem diversos métodos de formação de agrupamentos, entretanto estes não serão abordados por não fazerem parte do objetivo deste trabalho. Já os métodos de avaliação de agrupamentos se demonstram importantes ferramentas para avaliar a utilizaçõa de TG em células de manufatura

Os métodos de avaliação de agrupamentos podem ser divididos em seis tipos, segundo Sarker e Khan (2001): eficiência do grupo (CHANDRASEKHARAN; RAJAGOPALAN, 1989); eficácia do grupo (KUMAR; CHANDRASEKHARAN, 1990); eficácia ponderada do grupo (NG, 1993); índice do grupo (NAIR; NARENDRAN, 1996); medida do grupo (MILTENBURG; ZHANG, 1991); e eficiência ponderada do grupo (SARKER; KHAN, 2001).

O método de avaliação de eficiência de grupo permite a ponderação das incidências intracelulares e inter-celulares. A relação intra-celular se refere a quantidade de produtos que não possuem um número de processos comuns ao grupo. Por outro lado, a relação inter-celular se refere a quantidade de produtos que possuem processos incomuns ao grupo (SILVEIRA, 1994). Uma vantagem apresentada por este método está no fato de que este mantém um nível confiável e prático de informações necessárias.

A partir da formulação da matriz de produto e processo, registrando o valor "1" ao ocorrer a incidência e "0" a não ocorrência, o cálculo contido em Chandrasekharan e Rajagopalan (1989) resulta no valor de "N", na seguinte formulação:

$$
\begin{aligned}
& \mathrm{N}=\mathrm{qn} 1+(1-\mathrm{q}) * \mathrm{n} 2 \\
& 0 \leq \mathrm{q} \leq 1
\end{aligned}
$$

Onde: $\mathrm{N}=$ resultado da eficiência do grupo

$$
\text { n1 = Número de registros de " } 1 \text { " nos blocos celulares }
$$

Número total de registros nos blocos celulares (“0” e "1")

n2 = Número de registros de " 0 " fora dos blocos celulares

Número total de registros fora dos blocos celulares (" 0 " $\mathrm{e}$ " 1 ")

$\mathrm{q}=$ Fator de ponderação entre os registros inter e intra celulares. Se o grau de importância for o mesmo, o fator equivale a " 0,5 ”. Caso a importância das relações intra-celular for maior que a inter-celular, o fator de ponderação deve assumir um valor maior que 0,5. 
A formulação do exemplo contido na Tabela 1, onde os quadrados marcados formam os blocos celulares, demonstra o cálculo de eficiência:

Tabela 1- Exemplo de matriz de incidência produto e processo

\begin{tabular}{|l|c|c|c|c|}
\hline Processos/Produtos & Produto A & Produto B & Produto C & Produto D \\
\hline Operação 1 & 1 & 1 & & 1 \\
\hline Operação 2 & & 1 & & \\
\hline Operação 3 & 1 & 1 & & \\
\hline Operação 4 & 1 & & 1 & 1 \\
\hline Operação 5 & & & 1 & 1 \\
\hline
\end{tabular}

Fonte: Autores, 2007

$\mathrm{N}=0,5 *(9 / 12)+(1-0,5) *(8 / 12)$

$\mathrm{N}=70,8 \%$

\subsection{Benefícios da Manufatura Celular}

A maior parte dos trabalhos a cerca dos benefícios trazidos pela MC são relacionados a simulações matemáticas e pesquisas empíricas, comparando transformações ocorridas a partir da nova forma de organização da produção (SHAMBU et al., 1996). Assim, se torna importante destacar que a análise dos benefícios da MC deve ser relacionada ao tipo de organização de produção a ser substituído ou comparado.

Segundo Silveira (1994), grande parte das aplicações de MC se refere a sua implantação no lugar de arranjos físicos funcionais (AF). Nesses casos, os benefícios enfatizam a melhoria na qualidade dos produtos, aumento da utilização do operador, redução de setups, menor lead time, menor tempo de resposta, diminuição de produtos entre processos $(W I P)$ e, conseqüentemente, redução de custos (WEMMERLOV; HYER, 1989; WEMMERLOV; JOHNSON, 1997). Os resultados negativos em alguns indicadores também ocorrem na transição de AF para MC devido a alteração de arranjo físico (SHAMBU et al., 1996). Exemplos desvafováveis citam a queda no percentual de utilização de máquinas, perda de flexibilidade, custo do re-arranjo físico, duplicidade de maquinário (SURESH, 1992; MORRIS; TERSINE, 1994) e até problemas de resistências de operadores ao trabalho em equipe e a multifuncionalidade (WEMMERLOV; JOHNSON, 1997).

A substituição de linhas de produção por células de manufatura traz uma flexibilidade maior a produção, entretanto, isto também pode significar resultados desfavoráveis, tais como: aumento do tempo total de setups; perda de sinergia entre os processos em função da divisão de uma linha de produção única em mais de uma célula de trabalho; o aumento do tempo de atravessamento (flowtime); e o aumento do WIP (SURESH, 1991; MORRIS; TERSINE, 1990). Por outro lado, os 
benefícios mais comuns são: o aumento de flexibilidade de mix e volume de produção; a redução do tempo marginal de setup; a redução de lotes de fabricação (HYER; WEMMWERLOV, 2004).

Estes diferentes resultados levam a crer que a análise de benefícios da MC deve ser encarada de forma abrangente, pois pode envolver tanto aspectos positivos quanto negativos. Enquanto em uma transição de AF para MC, conforme explicado anteriormente, ocorre uma diminuição de flexibilidade, diminuição do tempo de resposta e redução de WIP. Já caso de uma transição de AP para MC ocorre exatamente o contrário: aumento do WIP, aumento do tempo de resposta e maior flexibilidade.

\subsection{Princípios da MC}

Os princípios da MC presentes neste artigo seguem a definição establecida por Hyer e Brown (1999), que identifica dois critérios básicos para identificação de células de manufatura: o primeiro critério se refere a satisfazer a caracterização de um arranjo físico celular baseado em tecnologia de grupo, sendo que, para alguns autores, o conceito de células de manufatura se restringe ao arranjo físico. Entretanto, Hyer e Brown (1999) adicionaram uma nova perpectiva, a partir do segundo critério que define a relação entre os elementos tempo, espaço e informação como primordial para o estabelecimento da MC. Tal relação é responsável pela obtenção dos principais benefícios trazidos por esta forma de organização do trabalho.

Assim, é permitida a existência de graus diferentes de relação entre aqueles três elementos, o que implica em diferentes resultados alcançados em uma célula de manufatura. A totalidade dos benefícios é alcançada apenas quando a célula de manufatura adere a disciplina de reunir, de forma harmônica, os três elementos, caracterizando assim uma célula física real. A distribuição desigual da relação entre os elementos resultaria em outros tipos de células de manufatura, com um menor número de benefícios. Este conceito foi constituído buscando o posicionamento da célula física real em relação aos elementos principais.

No que se refere ao elemento tempo, uma célula física real deve ter pouco atraso entre o final de uma tarefa e o início da próxima, além do baixo tempo de transferência e espera em relação aos produtos e materias. Em consequencia, a produção de pequenos lotes, baixo tempo de setup, treinamento multifucional e rodízio são exemplos de práticas que diminuem o efeito dos desperdícios de tempo entre atividades (HYER; BROWN, 1999)

O espaço é considerado fundamental na constituição de células de manufatura, sendo que a proximidade dos equipamentos é o elo de ligação entre os elementos tempo e informação. A proximidade reduz o desperdícios relativos a transferência de materiais e a troca de informações entre máquinas e operadores. A utilização de equipamentos menores e configurações físicas 
compactas, tais como os arranjos em "U” (BLACK, 1991), são exemplos de práticas que reforçam o elemento espaço.

A troca de informação é um princípio que aparece em poucos trabalhos relativos ao tema, mas que, impulsionada pelas práticas enxutas (MONDEN, 1987), foi incorporada como fundamental na organização de sistemas fabris. Para Hyer e Brown (1999) a troca de informação entre operadores e máquinas deve ser completa, precisa e acessível a todos, indicando metas, pedidos, especificações, procedimentos e disponibilidade de componentes.

A relação tempo-informação é a mais dinâmica dentre todas. Na realização de tarefas é necessário precisão no tempo, sendo que, informações completas e disponíveis podem ser utilizadas para diminuir os tempos operacionais. O espaço também influencia no fluxo de informação intracelular. A proximidade de pessoas, máquinas e processos aumenta o potencial de comunicação contínua entre os operadores e facilita a resolução rápida de problemas. Essa troca de informações permite que os operadores tomem conhecimento sobre o nível de estoque, problemas de qualidade, gargalos de produção, falta de componentes e outros fatores-chave do desempenho da célula. A redução de atrasos no transporte de materiais entre tarefas, faz da relação espaço-tempo mais uma importante relação da MC. Quanto maior a distância percorrida por um componente dentro da empresa, maior a probabilidade de atraso na produção por espera de material, envio a um local errado ou sofrer danos relativos ao manuseio (HYER; BROWN, 1999).

A classificação sugerida por Hyer e Brown (1999) leva em consideração que a célula física real apresenta a totalidade dos benefícios oferecidos pela $\mathrm{MC}$, e que os demais tipos de células de manufatura possuem deficiência em um ou mais destes elementos. Neste caso, cada uma das demais tipologias não teria a disciplina de uma célula física real em relação aos princípios da MC.

A figura 1 representa a relação entre as tipologias de célula de manufatura classificadas em contraponto ao elemento deficiente.

Figura 1 - Classificação de células de manufatura

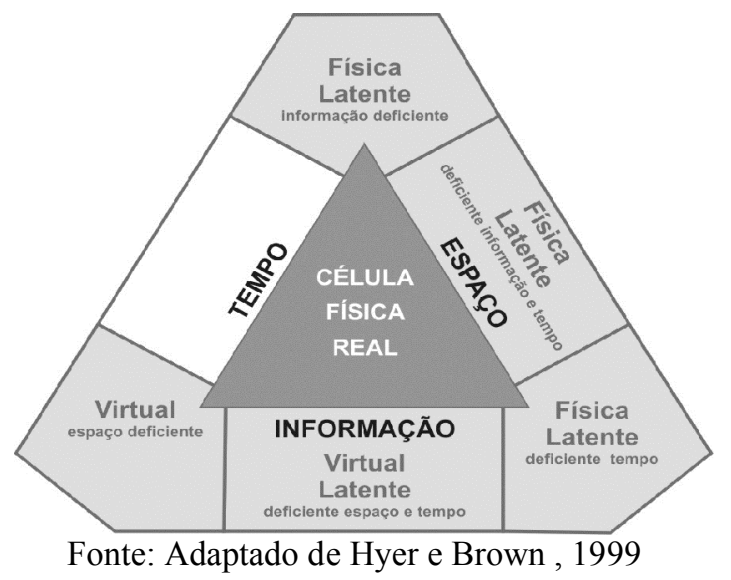


Os tipos possíveis de células de manufatura estão contidos na Figura 2 com uma breve descrição de como seria a relação ente os elementos.

Tabela 2 - Elementos deficientes e características da manufatura celular

\begin{tabular}{|l|l|l|}
\hline Tipo de célula & Deficiência & Descrição \\
\hline Virtual & Espaço & $\begin{array}{l}\text { Pessoas e equipamentos dedicados à uma família de produtos e o fluxo de } \\
\text { trabalho está ligado apenas ao tempo e informação }\end{array}$ \\
\hline Virtual latente & $\begin{array}{l}\text { Tempo e } \\
\text { Espaço }\end{array}$ & $\begin{array}{l}\text { Tarefas realizadas sequencialmente em locais separados e com atrasos de } \\
\text { movimentação de produto }\end{array}$ \\
\hline Física latente & Tempo & $\begin{array}{l}\text { Maquinário agrupado e informações disponíveis, mas com atrasos devido a } \\
\text { fatores relacionados ao tempo }\end{array}$ \\
\hline Física latente & Informação & $\begin{array}{l}\text { Maquinário agrupado e tarefas seguindo o fluxo sem atrasos, mas com pouco } \\
\text { ou nenhum fluxo de informações }\end{array}$ \\
\hline Física latente & $\begin{array}{l}\text { Tempo e } \\
\text { Informação }\end{array}$ & $\begin{array}{l}\text { Pessoas, equipamentos e tarefas agrupados, mas com tempo entre tarefas } \\
\text { longo e fluxo de informação pobre }\end{array}$ \\
\hline Inexistente & $\begin{array}{l}\text { Espaço e } \\
\text { Informação }\end{array}$ & $\begin{array}{l}\text { A presença de apenas tempo é muito pouco provável. A proximidade espacial } \\
\text { ou o fluxo de informação é fundamental para ocorrer o fluxo de produção. }\end{array}$ \\
\hline
\end{tabular}

Fonte: adaptado de Hyer e Brown , 1999

\section{Método de Pesquisa}

O modelo proposto foi construído a partir de uma revisão teórica sobre manufatura celular, seus principais benefícios e características. A partir deste modelo desenvolvido, foram escolhidas duas empresas que utilizam arranjos físicos celulares para realização de estudos de caso visando validar o modelo. A primeira empresa é denominada Lanches S.A. neste estudo, sendo esta uma multinacional do ramo alimentício e caracterizada por fornecer lanches rápidos. A empresa foi escolhida principalmente pela facilidade de visitação e análise e por adotar a organização da produção como um diferencial competitivo de manufatura (ZAWISLAK et al., 2003). O segundo caso é de uma empresa que fabrica armas, forjados, blindagens, capacetes, máquinas e ferramentas em geral, que será chamada de Forjas S.A. Esta empresa foi escolhida por apresentar arranjos físicos celulares característicos de indústrias do setor metal-mecânico, que, segundo Wemmerlöv e Hyer (1989), são as que mais beneficiam com as implantações de MC e onde essas foram bastante difundidas. Ambas as empresas reconhecem a manufatura e operações como forma de obter e sustentar vantagem competitiva.

A coleta de dados foi feita através de uma visita à cada empresa, onde foram entrevistados os gerentes, supervisores de produção e responsáveis de produção com objetivo de entender o processo produtivo e escolher uma célula para realizar o estudo. Após, foi realizada uma visita ao 
chão de fábrica durante um período de duas a quatro horas com os objetivos de entender o funcionamento da célula, de avaliar os fatores críticos e desenhar o layout produtivo. Os dados obtidos na observação foram analisados e discutidos em conjunto com os responsáveis dos setores, gerando as sugestões de melhorias. Foi avaliado um arranjo físico celular em cada uma das empresas, sendo que o critério de escolha foi a importância e complexidade de produção de acordo com as entrevistas feitas com a gerência.

\section{O Modelo MMCel}

O modelo é composto de quatro etapas. A primeira faz a identificação de uma célula de tecnologia de grupo, ou seja, responde ao primeiro critério do conceito de Hyer e Brown (1999) para identificar se há dedicação a uma família de produtos. A segunda etapa avalia os fatores críticos de sucesso na célula objeto de estudo, associando tais fatores aos elementos tempo, espaço e informação. A partir da segunda etapa, a terceira etapa classifica a célula de manufatura de acordo com os seis tipos existentes. A quarta etapa é utilizada para identificar e propor melhorias.

\subsection{Primeira Etapa: Identificar Família de Produtos}

Foi utilizado o indicador de eficiência de agrupamento com o intuito de avaliar o grau de utilização de tecnologia de grupo e confirmar a utilização de um arranjo físico celular, conforme a definição do mesmo.

Esta etapa inicia pela construção da matriz produto e processos, que apresenta a lista de produtos fabricados nas colunas e os processos produtivos ou equipamentos contidos no arranjo físico em suas linhas. A partir desta matriz, se utiliza o método de avaliação de efíciência de agrupamento, segundo Chandrasekharan e Rajagopalan (1989). Como a avaliação ser feita em apenas um agrupamento de cada vez, o fator de ponderação será utilizado como valor "1", pois serão avaliadas apenas as relações intra-celulares.

Este indicador foi escolhido por apresentar um nível confiável e prático de informações. Para fins desta etapa, um arranjo físico deve apresentar um índice maior que $75 \%$ na eficiência do grupo para ser considerado um arranjo físico celular, conforme sugerido por Duggan (1998). Desta forma, caso o arranjo apresente este indicador de valor igual ou maior ao estipulado, será considerado um arranjo físico celular e estará satisfazendo a primeiro critério estabelecido por Hyer e Brown (1999) para uma célula de manufatura.

\subsection{Segunda Etapa: Avaliar dos Fatores Críticos}


O objetivo desta etapa é avaliar a interação entre os elementos tempo, espaço e informação, de acordo com o segundo critério dos princípios da MC. Os fatores críticos foram determinados a partir de diversos trabalhos sobre o tema (HUNTER et al., 2005; MONDEN, 1983; GUIMARÃES et al., 2005; SUZAKI, 1983; GHOSH, 1990; WEMMERLÖV; HYER, 1989; KANNAN; GHOSH, 1995; HYER et al. 1999).

A tabela 3 contém os fatores críticos e suas relações com os elementos tempo, espaço e informação, sua descrição e seus benefícios. Com o intuito de elaborar um modelo que possa captar a relação harmônica ou desarmônica entre os elementos, foi estabelecido que apenas cinco fatores críticos se relacionassem com cada um destes elementos. As interações foram consideradas apenas em seu caráter mais significativo, desconsiderando as relações fracas existentes entre fatores e elementos.

O nível de implantação de cada um dos fatores críticos listados na figura 3 deve ser avaliado, levando em consideração uma escala de zero a três (0-inexistente; 1-fraco; 2-médio; 3forte) na célula onde o modelo está sendo aplicado. O tempo necessário para avaliar cada fator pode variar dependendo da situação, mas é estimado que a observação do funcionamento da célula deva ser de, no mínimo, duas horas de trabalho. Em alguns casos, as células podem operar com um número variado de operadores, alterando até em um mesmo turno de trabalho. Nesses casos, é sugerido que esta etapa seja realizada de acordo com a situação mais usual de funcionamento da célula.

A tabela 3 pode servir como também como ferramenta para a aplicação do modelo, sendo que o importante para a próxima etapa é o resultado da soma das intensidades de existência dos fatores críticos de cada elemento.

Para uma melhor aplicação desta proposta, é sugerido que seja feito um desenho da disposição física e funcionamento da célula analisada, o qual poderá auxiliar na avaliação de alguns dos fatores críticos, como para os fatores quatro, cinco, oito e onze. Além disso, o desenho poderá ser utilizado como base para futura aplicação em processos contínuos de melhoria. Também pode ser necessário consultar documentos, como por exemplo tempos padrão, indicadores de setup, ferramentas de planejamento e controle de produção, bem como entrevistar trabalhadores e gerentes. 
Tabela 3 - Relação entre Fatores Críticos x Variáveis Analisadas x Benefícios

\begin{tabular}{|c|c|c|c|c|c|}
\hline Fatores Críticos & Descrição & Tempo & Espaço & Inform. & Benefícios \\
\hline $\begin{array}{l}01 . \text { Tempos de setup } \\
\text { reduzido }\end{array}$ & $\begin{array}{l}\text { Tempos de setup entre os produtos da célula, } \\
\text { em relação aos produtos grupo A, no } \\
\text { processo gargalo. }\end{array}$ & $\mathbf{X}$ & & & $\begin{array}{l}\text { Maior flexibilidade e mais capacidade de manter o } \\
\text { fluxo de produção. }\end{array}$ \\
\hline $\begin{array}{l}\text { 02. Mínimo estoque entre } \\
\text { processo }\end{array}$ & $\begin{array}{l}\text { Comparação entre estoque entre processos } \\
\text { da célula e produção diária. }\end{array}$ & $\mathbf{x}$ & $\mathbf{X}$ & & $\begin{array}{l}\text { Redução de perdas por estoque, menor tempo de } \\
\text { ciclo. }\end{array}$ \\
\hline $\begin{array}{l}\text { 03. Tempos dos processos } \\
\text { da família balanceados }\end{array}$ & Indicador de eficiência do balanceamento & $\mathbf{X}$ & & & $\begin{array}{l}\text { Otimização da utilização de recursos homem/máquina, } \\
\text { minimizar os efeitos da restrição de gargalo. }\end{array}$ \\
\hline $\begin{array}{l}\text { 04. Tempo de } \\
\text { movimentação/tempo } \\
\text { tarefas }\end{array}$ & $\begin{array}{l}\text { Relação entre a perda por movimentação dos } \\
\text { operadores sobre o tempo de processamento. }\end{array}$ & $\mathbf{X}$ & $\mathbf{X}$ & & $\begin{array}{l}\text { Redução de perdas de movimentação, otimização das } \\
\text { tarefas. }\end{array}$ \\
\hline $\begin{array}{l}\text { 05. Célula em tamanho } \\
\text { reduzido, forma compacta } \\
\text { (U, V, L, circular, por } \\
\text { exemplo) }\end{array}$ & $\begin{array}{l}\text { Dimensões da célula e número de operadores } \\
\text { em relação a capacidade do layout em } \\
\text { viabilizar a troca de materiais entre todos os } \\
\text { operadores. }\end{array}$ & & $\mathbf{X}$ & $\mathbf{X}$ & $\begin{array}{l}\text { Facilita o controle das tarefas, a troca de informações } \\
\text { entre operadores e assegura o fluxo de } \\
\text { materiais/informações. }\end{array}$ \\
\hline 06. Equipamentos móveis & $\begin{array}{l}\text { Possibilidade de rearranjo da maior parte dos } \\
\text { equipamentos de acordo com a demanda. }\end{array}$ & & $x$ & & $\begin{array}{l}\text { Aumenta flexibilidade de adaptação a flutuações de } \\
\text { mix e volume de produção. }\end{array}$ \\
\hline $\begin{array}{l}07 . \text { Ocorre troca de } \\
\text { informações entre } \\
\text { operadores/máquinas }\end{array}$ & $\begin{array}{l}\text { Grau de utilização de comunicação (sonora e } \\
\text { visual) entre operadores e ou máquinas. }\end{array}$ & & & $\mathbf{X}$ & $\begin{array}{l}\text { Viabiliza um maior controle dos processos, propicia } \\
\text { troca de informações entre operadores. }\end{array}$ \\
\hline $\begin{array}{l}08 . \text { Visibilidade de toda a } \\
\text { célula }\end{array}$ & $\begin{array}{l}\text { Viabilidade de visualização dos fluxos de } \\
\text { produtos, processos e operações por todos } \\
\text { os operadores. }\end{array}$ & & $\mathbf{x}$ & $\mathbf{X}$ & $\begin{array}{l}\text { Melhora o controle dos processos e possibilita a troca } \\
\text { de informações entre os operadores. }\end{array}$ \\
\hline $\begin{array}{l}\text { 09. Sistema de controle } \\
\text { perceptível }\end{array}$ & $\begin{array}{l}\text { Grau de aplicação de sistemas de controle } \\
\text { que proporcionem rápido feedback aos } \\
\text { operadores disponibilize rapidamente a } \\
\text { informação aos operadores. }\end{array}$ & & & 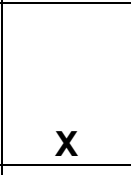 & $\begin{array}{l}\text { Permite melhora na qualidade e diminuição de perdas } \\
\text { no processo. }\end{array}$ \\
\hline $\begin{array}{l}\text { 10. Multifuncionalidade e } \\
\text { Rodízio }\end{array}$ & $\begin{array}{l}\text { Capacidade dos operadores de realizar } \\
\text { múltiplas tarefas. Freqüência de rotação dos } \\
\text { operadores pelos diversos postos de trabalho. }\end{array}$ & $\mathbf{X}$ & & & $\begin{array}{l}\text { Aumento da flexibilidade através de perdas menores } \\
\text { de tempo em mudança de produtos e alterações de } \\
\text { postos de trabalho. }\end{array}$ \\
\hline $\begin{array}{l}\text { 11. Organização física da } \\
\text { célula conforme fluxo } \\
\text { dominante }\end{array}$ & $\begin{array}{l}\text { Grau de acomodação do layout conforme o } \\
\text { fluxo dominante dos produtos. }\end{array}$ & & & $\mathbf{X}$ & $\begin{array}{l}\text { Facilita o controle e reduz interferências entre fluxos a } \\
\text { operação, aumentando a capacidade de detecção e } \\
\text { perdas. }\end{array}$ \\
\hline
\end{tabular}

Fonte: Autores, 2007 


\subsection{Terceira Etapa: Classificar em relação aos Princípios}

A partir da avaliação dos fatores críticos, a terceira etapa fundamenta-se em classificar a intensidade de cada um dos três elementos e suas interações. O grau de intensidade resulta da pontuação recebida na avaliação de fatores críticos, assim, cada elemento que estiver relacionado a cada um dos fatores crítico recebe a soma de todos os pontos relativos a estes. No caso dos fatores críticos que estão relacionados a mais de um elemento, ambos os elementos recebem o valor da pontuação.

O resultado de cada um dos elementos deve ser transformado em percentual de acordo com o máximo possível, ou seja, se divide por 15. Para se considerar um elemento como deficiente, o resultado tem de ser inferior a $65 \%$, pois, desta forma, a média da soma dos fatores críticos teria um resultado menor que "2". O resultado torna possível verificar quais os elementos estão deficientes e quais não estão deficientes para seguir para a classificação de tipologia.

A nomenclatura apresentada na Figura 2 é utilizada para classificar a célula de manufatura em: Virtual Latente (deficiente em tempo e espaço); Virtual (deficiente em espaço); Física Latente (deficiente em informação e ou tempo); ou uma Célula Física Real.

Assim, a célula que apresentar um os três elementos superiores a $65 \%$ na avaliação será considerada uma célula física real. No caso de apresentar deficiência nos três elementos, este será considerado apenas um arranjo físico celular, por não apresentar pouquissima intensidade e nenhuma interação entre os elementos.

\subsection{Quarta Etapa: Propor Melhorias}

A última etapa tem como objetivo identificar e propor melhorias. Partindo do pressuposto de uma célula física real não apresentar a deficiência em nenhum dos elementos, esta etapa busca evidenciar o caminho para outros tipos de células se tornarem físicas reais. No caso de ser considertada uma célula física real, o objetivo passa a ser melhorar o seu desempenho em relação aos benefícios da MC.

O primeiro passo é montar uma equipe. Caso a empresa não tenha uma forma de organizar o processo de melhorias, sugere-se que esta equipe seja formada por operadores da célula, lideres e supervisores. Os chamados grupos kaizen, utilizados por empresas enxutas, possuem estas características. São grupos de funcionários treinados para identificar, propor e implementar melhorias, e serão considerados como ideais para guiar a aplicação deste modelo.

O segundo passo é montar uma tabela com os fatores críticos que apresentaram valores menores do que três pontos na etapa 2, com as colunas de problemas encontrados e melhorias 
vislumbradas. O grupo deve se reunir para completar a tabela com as informações de quais foram os problemas que geraram uma menor pontuação e quais as melhorias que podem ser feitas para aumentar este resultado. Visitas a célula e entrevistas com operadores podem auxiliar no preenchimento desta tabela.

Ao completar a tabela, é necessário estabelecer um cronograma de implantação das melhorias. Sugere-se que o grupo relacione o grau de dificuldade e custos de cada uma das melhorias. Entretanto, a elaboração de um plano de ações deve ser focado em aprimorar aqueles fatores que estão ligados a elementos deficiêntes. Os elementos mais deficientes em conjunto com aqueles que podem trazer uma maior diferença na pontuação estabelecida na etapa 2 devem ser priorizados.

\section{Estudos de caso de aplicação do modelo}

\subsection{Primeiro Caso: Empresa Lanches S.A.}

A Lanches S.A é uma empresa multinacional de serviço rápido de alimentação que atua em 118 países, empregando cerca de 1,5 milhão de funcionários e atendendo em média 47 milhões de clientes por dia, em 2005. Seus produtos são constituídos por sanduíches, empanados, batatas fritas, sobremesas e bebidas. O estudo foi realizado em uma loja localizada em Porto Alegre, com mais de 80 funcionários em três turnos de trabalho. O fluxo de produção no qual foi escolhida uma célula de trabalho para a avaliação é a montagem de sanduíches com carnes finas, por ser o produto de maior valor para a empresa e possuir uma gama maior de processos.

A produção de sanduíches inicia pelos ingredientes, carnes, condimentos e pães, sendo retirados de câmaras frias e colocados à disposição para a fabricação. O processo de fabricação é iniciado com a colocação das carnes na chapa pelo operador 1 , conforme a figura 4 , de acordo com a ordem de produção informada verbalmente por um operador posicionado ao lado da célula. $\mathrm{O}$ operador 1 também insere os pães em tostadeiras e aguarda os tempos de processamento. Ao final do processamento na tostadeira, o pão é retirado pelo operador 1, que coloca a carne sobre a metade inferior do sanduíche. O operador 2 se posiciona na mesa de montagem e é responsável pela colocação de ingredientes como queijo, salada, molhos e etc. Após a montagem, o produto é passado para o operador responsável pela programação e controle de produção, que embala e disponibiliza o produto na estufa. Este último operador não foi considerado na análise do arranjo físico.

A figura 4 mostra o arranjo físico e fluxo de produção e materiais na célula $\mathrm{A}$, que foi objeto de estudo do caso. A avaliação foi realizada com dois operadores, pois esta é o modo mais utilizado 
para a produção, sendo que na Figura 4 estão representados de forma pontilhada os postos onde ficariam outros operadores quando estão trabalhando em quatro funcionários.

Figura 2 - Arranjo físico da célula A na empresa Lanches S.A.

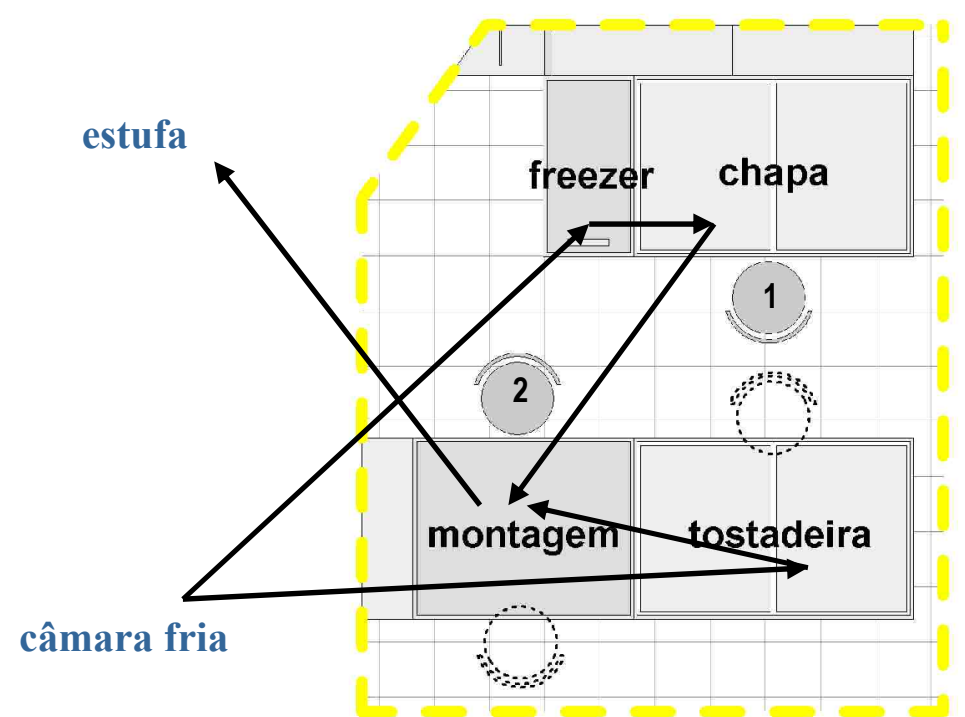

Fonte: Autores, 2007

\subsubsection{Etapa 1: Família de Produtos}

A primeira etapa do modelo é a identificação das características das células em relação à tecnologia de grupo. Assim, foi desenvolvida a figura 5, que contêm os produtos que passam pela célula analisada em relação aos processos produtivos. Neste caso, o índice de eficiência do grupo, cujo cálculo está detalhado na sessão 2.3 , resultou em $80 \%$, ou seja, este arranjo físico está organizado de acordo com a tecnologia de grupo. Abaixo se pode ver o cálculo em detalhe:

$\mathrm{N} 1=1 *(16 / 20)$

Tabela 4 - Matriz produto e processo da empresa Lanches S.A.

\begin{tabular}{|l|c|c|c|c|}
\hline Processos/Produtos & Sand A & Sand B & Sand C & Sand D \\
\hline Câmara fria & $\mathbf{1}$ & $\mathbf{1}$ & $\mathbf{1}$ & $\mathbf{1}$ \\
\hline Balcão de Montagem & $\mathbf{1}$ & $\mathbf{1}$ & $\mathbf{1}$ & $\mathbf{1}$ \\
\hline Chapa & $\mathbf{1}$ & $\mathbf{1}$ & $\mathbf{1}$ & $\mathbf{1}$ \\
\hline Tostadeira dupla & & 1 & 1 & 1 \\
\hline Tostadeira tripla & $\mathbf{1}$ & & & \\
\hline
\end{tabular}

Fonte: Autores, 2007

\subsubsection{Etapa 2: Avaliação dos Fatores Críticos}


A observação do funcionamento da célula foi feita durante meio turno de trabalho, sendo que o resultado é apresentado na figura 6. As células sombreadas representam aqueles fatores que não atingiram pontuação plena.

Tabela 5 - Resultado de avaliação dos fatores críticos na célula A

\begin{tabular}{|l|c|c|c|}
\hline Fatores Críticos & Tempo & Espaço & Informação \\
\hline 01. Tempos de setup reduzido & $\mathbf{3}$ & & \\
\hline 02. Mínimo estoque entre processo & $\mathbf{2}$ & $\mathbf{2}$ & \\
\hline 03. Tempos dos processos da família balanceados & $\mathbf{3}$ & & \\
\hline 04. Tempo de movimentação / Tempo de tarefas & $\mathbf{2}$ & $\mathbf{2}$ & \\
\hline 05. Célula em tamanho reduzido & & $\mathbf{3}$ & $\mathbf{3}$ \\
\hline 06. Equipamentos móveis (flexíveis) & & $\mathbf{2}$ & \\
\hline 07. Ocorre troca de informações entre operadores/maquinas (incluindo visuais) & & & $\mathbf{3}$ \\
\hline 08. Visibilidade de toda a célula & & $\mathbf{2}$ & $\mathbf{2}$ \\
\hline 09. Sistema de controle perceptível & & & $\mathbf{1}$ \\
\hline 10. Multifuncionalidade e Rodízio & $\mathbf{3}$ & \\
\hline 11. Organização física da célula conforme fluxo dominante & & & $\mathbf{3}$ \\
\hline \multicolumn{1}{|c|}{ TOTAL } & $\mathbf{1 3}$ & $\mathbf{1 1}$ & $\mathbf{1 2}$ \\
\hline
\end{tabular}

Fonte: Autores, 2007

\subsubsection{Etapa 3: Classificação}

A pontuação resultante para cada elemento na etapa 2 apresentou um desempenho equilibrado. $\mathrm{O}$ arranjo físico avaliado possui a relação forte entre tempo, espaço e informação entre operações e entre operadores. $\mathrm{O}$ arranjo alcançou graus bastante elevados nos elementos de tempo e informação, $87 \%$ e $80 \%$, respectivamente, referente à divisão do total de pontos possíveis, 15 , pelo total alcançado por cada elemento. O elemento espaço também teve um escore alto, alcançando $74 \%$ e, assim, a célula alcançou um escore maior que $65 \%$ nos três lementos, caracterizando-a como uma célula física real.

\subsubsection{Etapa 4: Análise e Proposição de Melhorias}

A tabela 7 é o resultado da etapa 4, no qual se sugere a implementação das melhorias descritas a partir da análise dos fatores críticos que não atingiram a pontuação máxima. Essas melhorias buscam aprimorar a célula estudada vislumbrando a pontuação máxima nos três elementos. 
Tabela 7 - Análise e proposição de melhorias na célula A

\begin{tabular}{|l|l|l|}
\hline Fatores Críticos & Problemas & Melhoria \\
\hline $\begin{array}{l}\text { 02. Mínimo estoque } \\
\text { entre processo }\end{array}$ & $\begin{array}{l}\text { Estoque de matérias-primas na entrada } \\
\text { da célula. }\end{array}$ & $\begin{array}{l}\text { Alimentação de materiais mais freqüente } \\
\text { e, consequentemente, menores lotes. }\end{array}$ \\
\hline $\begin{array}{l}\text { 04. Tempo de } \\
\text { movimentação/tarefas }\end{array}$ & $\begin{array}{l}\text { Perda de tempo na movimentação em } \\
\text { razão do fluxo de produtos ser manual. }\end{array}$ & $\begin{array}{l}\text { Reorganização a um formato de "L" e ou } \\
\text { um sistema de calhas por gravidade. }\end{array}$ \\
\hline $\begin{array}{l}\text { 06. Equipamentos } \\
\text { móveis }\end{array}$ & $\begin{array}{l}\text { Alguns equipamentos não apresentam } \\
\text { mobilidade e outros possuem limitações } \\
\text { em relação a pontos elétricos }\end{array}$ & $\begin{array}{l}\text { Aumentar a quantidade de pontos } \\
\text { elétricos. }\end{array}$ \\
\hline $\begin{array}{l}\text { 08. Visibilidade de } \\
\text { toda a célula }\end{array}$ & $\begin{array}{l}\text { Barreiras visuais (fios elétricos e e } \\
\text { estoques) que impedem a visualização } \\
\text { dos processos por todos os operadores. }\end{array}$ & $\begin{array}{l}\text { Realocação do estoque e a alimentação } \\
\text { elétrica pelo piso. }\end{array}$ \\
\hline $\begin{array}{l}\text { 09. Sistema de controle } \\
\text { perceptível }\end{array}$ & $\begin{array}{l}\text { Programação de produção verbal } \\
\text { dificulta o controle de produção e } \\
\text { deficiência de padrões de conformidade }\end{array}$ & $\begin{array}{l}\text { Controle de produção baseado em gestão } \\
\text { visual para tornar claro aos padrões de } \\
\text { qualidade e processos. }\end{array}$ \\
\hline
\end{tabular}

Fonte: Autores, 2007

\subsection{Segundo Caso: Empresa Forjas S.A.}

A Forjas S.A é uma empresa multinacional de grande porte que fabricas armas, forjados, blindagens, capacetes, máquinas e ferramentas em geral. A divisão de armas da empresa é uma das maiores do mundo neste segmento e tem grande participação no seu faturamento anual, sendo este escolhido para avaliação. Atualmente, a divisão de armas fabrica revólveres, pistolas, carabinas e armas policiais em três fábricas localizadas em Porto Alegre.

Neste caso, diferente do anterior, foi necessária a escolha de uma parte do fluxo de produção para a avaliação, pois o processo produtivo como um todo na fábrica possuí diversas etapas diferentes. A fábrica de revolveres conta com mais de 150 funcionários de chão-de-fábrica, composta por processos de usinagens, polimentos, banhos químicos, montagens e testes das armas. O arranjo físico escolhido para o estudo se encontra em uma etapa intermediária do fluxo de produção de revolveres.

No arranjo físico avaliado são feitas pequenas atividades de usinagem na estrutura principal que irá ser montado o revolver, a chamada armação. Os quatro modelos diferentes que passam por este arranjo físico possuem três caminhos distintos, sendo que os revolveres A 5 tiros e A 6 tiros apresentam o mesmo fluxo de produção. O produto B 22 percorre o fluxo total dos processos que compõe o arranjo físico, enquanto o C 5 tiros necessita de dois processos a menos que o B22. O arranjo físico pode ser visto na figura 8 , com os fluxos de produção de cada produto. 
Figura 3 - Layout da célula B colocar legenda de cores em função do modelo de revolver.

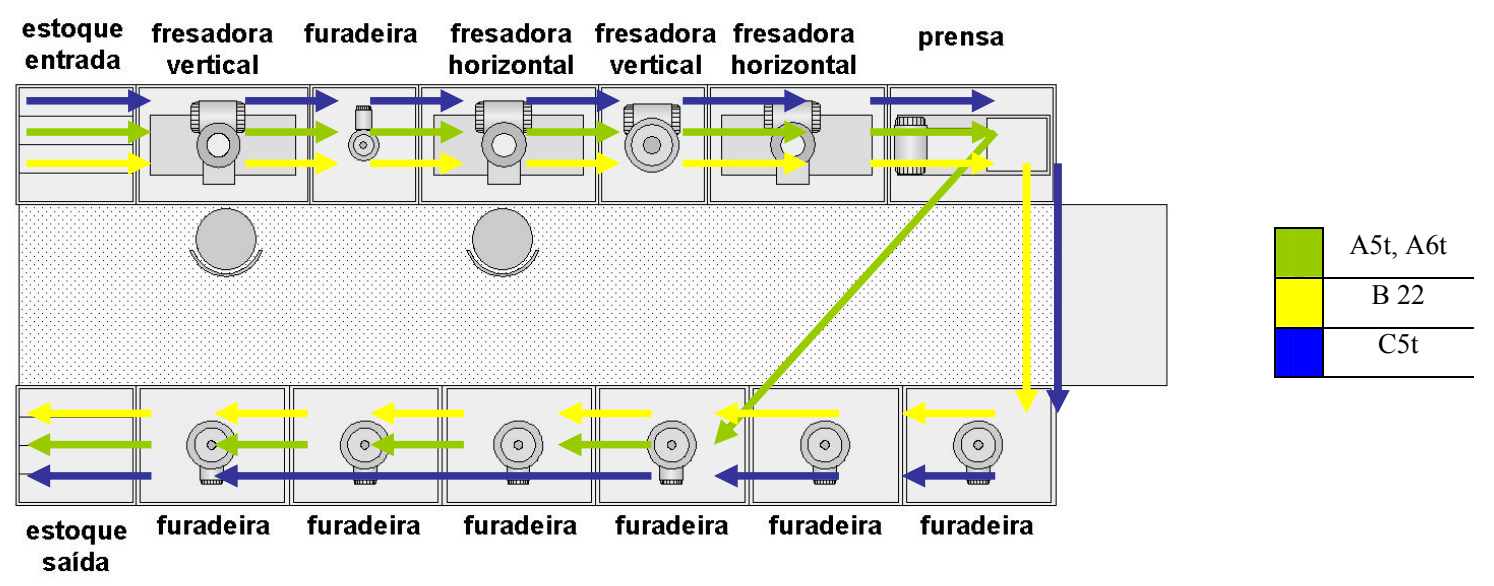

Fonte: Autores, 2007

\subsubsection{Etapa 1: Família de Produtos}

A matriz de produto e processo apresentada na figura 9, confere ao arranjo físico a característica de arranjo físico celular baseado em tecnologia de grupo. O índice de eficiência do grupo alcançou a marca de 87,5 \%, de acordo com a fórmula apresentada na sessão 2.3.

Tabela 7 - Matriz produto e processo da célula B nas Forjas S.A.

\begin{tabular}{|l|c|c|c|c|}
\hline Processos/Produtos & A5t & A6t & B22 & C5t \\
\hline Fresadora Vertical 1 & $\mathbf{1}$ & $\mathbf{1}$ & $\mathbf{1}$ & $\mathbf{1}$ \\
\hline Furadeira 1 & $\mathbf{1}$ & $\mathbf{1}$ & $\mathbf{1}$ & $\mathbf{1}$ \\
\hline Fresadora Horizontal 1 & $\mathbf{1}$ & $\mathbf{1}$ & $\mathbf{1}$ & $\mathbf{1}$ \\
\hline Fresadora Vertical 2 & $\mathbf{1}$ & $\mathbf{1}$ & $\mathbf{1}$ & $\mathbf{1}$ \\
\hline Fresadora Horizontal 2 & $\mathbf{1}$ & $\mathbf{1}$ & $\mathbf{1}$ & $\mathbf{1}$ \\
\hline Prensa & $\mathbf{1}$ & $\mathbf{1}$ & $\mathbf{1}$ & $\mathbf{1}$ \\
\hline Furadeira 2 & & & 1 & 1 \\
\hline Furadeira 3 & & & 1 & 1 \\
\hline Furadeira 4 & $\mathbf{1}$ & $\mathbf{1}$ & $\mathbf{1}$ & $\mathbf{1}$ \\
\hline Furadeira 5 & $\mathbf{1}$ & $\mathbf{1}$ & $\mathbf{1}$ & \\
\hline Furadeira 6 & $\mathbf{1}$ & $\mathbf{1}$ & $\mathbf{1}$ & \\
\hline Furadeira 7 & $\mathbf{1}$ & $\mathbf{1}$ & $\mathbf{1}$ & $\mathbf{1}$ \\
\hline
\end{tabular}

Fonte: Autores, 2007

\subsubsection{Etapa 2: Avaliação dos Fatores Críticos}

O resultado da avaliação do funcionamento do arranjo físico foi feito durante duas horas de trabalho é apresentado na figura 10. A avaliação dos fatores críticos resultou em sete fatores que não atingiram pontuação máxima. 
Tabela 8 - Avaliação de fatores críticos na célula B

\begin{tabular}{|c|c|c|c|}
\hline Fatores Críticos & Tempo & Espaço & Informação \\
\hline 01. Tempos de setup reduzido & 3 & & \\
\hline 02. Mínimo estoque entre processo & 3 & 3 & \\
\hline 03. Tempos dos processos da família balanceados & 3 & & \\
\hline 04. Tempo de movimentação / Tempo de tarefas & 2 & 2 & \\
\hline 05. Célula em tamanho reduzido & & 2 & 2 \\
\hline 06. Equipamentos móveis (flexíveis) & & 3 & \\
\hline 07. Ocorre troca de informações entre operadores/maquinas (incluindo visuais) & & & 2 \\
\hline 08. Visibilidade de toda a célula & & 3 & 3 \\
\hline 09. Sistema de controle perceptível & & & 0 \\
\hline 10. Multifuncionalidade e Rodízio & 2 & & \\
\hline 11. Organização física da célula conforme fluxo dominante & & & 2 \\
\hline TOTAL & 13 & 13 & 9 \\
\hline
\end{tabular}

Fonte: Autores, 2007

\subsubsection{Etapa 3: Classificação}

A soma dos resultados relacionados a cada elemento na avaliação de fatores críticos apresenta uma deficiência a nível de informação, caracterizando, assim, como uma célula física latente em informação. A informação é o elemento menos presente nesta célula de manufatura com apenas $60 \%$ de pontos alcançados, resultado da divisão de 9 pontos por 15 pontos. De outro lado, os elementos tempo e espaço apresentaram alto desempenho neste caso, com mesmo escore de $87 \%$, resultado de 13 pontos atingidos.

\subsubsection{Etapa 4: Análise e Proposição de Melhorias}

A figura 11 apresenta os problemas que levaram a pontuação mais baixa nos fatores críticos e as melhorias sugeridas.

Tabela 9 - Análise e proposição de melhorias na célula B

\begin{tabular}{|c|c|c|}
\hline Fatores Críticos & Problemas & Melhorias \\
\hline $\begin{array}{l}\text { 04. Tempo de movimentação / } \\
\text { Tempo de tarefas }\end{array}$ & $\begin{array}{l}\text { Alto tempo de movimentação devido a } \\
\text { grande número de processos para poucos } \\
\text { operadores e transporte intracelular feito } \\
\text { manualmente. }\end{array}$ & $\begin{array}{l}\text { Diminuir o tamanho da célula ou aumentar } \\
\text { número de operadores }\end{array}$ \\
\hline 05. Célula em tamanho reduzido & $\begin{array}{l}\text { Distância entre processos e dificuldades de } \\
\text { interação entre operadores }\end{array}$ & $\begin{array}{l}\text { Analisar a possibilidade de dividir em duas } \\
\text { ou mais células. }\end{array}$ \\
\hline $\begin{array}{l}\text { 07. Ocorre troca de informações } \\
\text { entre operadores/maquinas }\end{array}$ & $\begin{array}{l}\text { Sem dispositivos ou mecanismos de troca de } \\
\text { informações e dificuldade de troca verbal de } \\
\text { informações devido ao ruído intenso. }\end{array}$ & $\begin{array}{l}\text { Sistema de Poka Yoke visando troca de } \\
\text { informações entre máquinas e operadores. }\end{array}$ \\
\hline $\begin{array}{l}\text { 09. Sistema de controle } \\
\text { perceptível }\end{array}$ & $\begin{array}{l}\text { Falta de sistemas de controle de produção e } \\
\text { controle de qualidade }\end{array}$ & $\begin{array}{l}\text { Criar sistemas de controle de produção e de } \\
\text { garantia da qualidade }\end{array}$ \\
\hline
\end{tabular}




\begin{tabular}{|l|l|l|}
\cline { 2 - 3 } 10. Multifuncionalidade e Rodízio & $\begin{array}{l}\text { Operadores especialistas em suas } \\
\text { operações, não há rodízio. }\end{array}$ & $\begin{array}{l}\text { Estabelecer rodízio e treinamentos } \\
\text { multifuncionais }\end{array}$ \\
\hline $\begin{array}{l}\text { 11. Organização física da célula } \\
\text { conforme fluxo dominante }\end{array}$ & $\begin{array}{l}\text { Maior volume de produção não utiliza alguns } \\
\text { processos }\end{array}$ & Rever famílias de produtos \\
\hline
\end{tabular}

Fonte: Autores, 2007

\section{Conclusões}

Através da aplicação em duas células de manufatura de diferentes empresas em setores industriais diversos, o modelo proposto indicou possuir potencial como ferramenta de avaliação da manufatura celular. Além disto, o modelo demostrou uma facilidade de aplicação, sendo necessário apenas um dia de visita a cada uma das empresas.

As principais dificuldades enfrentadas na concepção do modelo foram relativas à escolha e delimitação dos fatores críticos. A enfase quase majoritária de trabalhos que buscam apenas o enfoque quantitativo relacionado a tecnologia de grupo dificultou a abordatem de critérios que estivessem ligados a definição sociológica presente em Hyer e Brown (1999). Ainda em relação aos fatores críticos, a dificuldade de estabelecer padrões de pontuação e a subjetividade de cada um deles ainda pode gerar dificuldades para futuras aplicações do modelo.

No intuito de validar a sua eficiência e levantar outras limitações, é necessário um maior número de aplicações em diferentes tipos de arranjos físicos. Isso também abriria espaço para a identificação de padrões de desempenho da manufatura celular em diferentes ambientes fabris, permitindo uma comparação entre empresas e a realização de benchmarking.

Por fim, levando em consideração que muitas implantações de células de manufatura ocorrem no contexto de iniciativas de produção enxuta, há oportunidade de ampliação do modelo para abranger tal filosofia de produção. Nesta caso, deve-se levar em consideração quais dos fatores críticos referem-se à produção enxuta, ou até mesmo aumentar o número de fatores analisados para contemplar esta nova perspectiva. Alguns dos principais benefícios e vantagens da MC estão intimamente ligados aos princípios defendidos pela produção enxuta, tais como fluxo de valor, fluxo contínuo e Just-in-time.

\footnotetext{
Abstract

The objective of this paper is to propose a model for assessing layouts from a cellular manufacturing $(\mathrm{CM})$ perspective. In this paper, it is considered that the appearance of a work flow in wich tasks and those who perform them are intimate connected in terms of time, space and information is a key characteristic of CM. The model is divided in four stages: (a) product family identification, (b) assessment of critical factors of CM, (c) classification of cell type; and (d) proposal for improvement in cell peformance. Two cases studies were conducted to test the model. In both studies, the model proved to be useful for identifying weaknesses and strengths of the cells that were investigated.
} 
Key-words: cellular manufacturing; work organization; layout evaluation.

\section{Referências}

BLACK, J.T. The design of the factory with a future. New York: McGraw-Hill, 1991.

BURBIDGE, J L. The First Step in Planning Group Tecnology. International Journal of Production Economics, v 43, p.261-266, 1996.

crossef

CHANDRASEKHARAN, M.; RAJAGOPALAN, R. GROUP-ABILITY: an analysis of the properties of binary data matrices for group technology. International Journal of Production Research, vol 27, pg. 1035-1052, 1989.

crossef

DROLET, J; ABDULnOUR, G, RHEAULT, M. The Cellular Manufactoring Evolution. Computers and Industrial Enginnering, $v 31, \mathrm{n}^{\circ} 1 / 2$, p.139-142, 1996.

cross ${ }^{\text {ref }}$

DUGGAN, K. Facilitiers Design for Lean manufacturing. Institute of Industrial Engineers Solutions, v 30, issue $12,1998$.

GHOSH, S. Equipament Investment Decision Analysis in Cellular Manufacturing. International Journal of Operations and Production Management, 1990.

GUIMARAES, L; SAURIN, T; ANZANELLO, M; SILVA, S; LEMOS, F; WELTER, A; ABECH ,M. Eliminação de Perdas Produtivas pela Implementação da Manufatura Celular. Encontro Nacional de Engenharia de Produção, Porto Alegre, 2005.

HAYES, G.; WHEELWRIGHT, S. C. Link manufacturing process and product life cylces. Harvard Business Review, january-february, 1979.

HUNTER, S; BULLARD, S; STEELE, P. Lean Production in the furniture industry: The double D assembly cell. Forrest Products Journal, v 54, n 4, 2004.

HYER, N L.; BROWN, K A. The Discipline of Real Cells. International Journal of Operations Management, v 17, p.557-574, 1999.

cross ${ }^{\text {ref }}$

HYER, N L.; BROWN, K A.; ZIMMERMAN, S. A social-technical systems approach to cell design: case study and analysis. Journal of Operations Management, v 17, p.179-203, 1999.

crossef

HYER, N.; WEMMERLOV, U. Cell Manufacturing: the hard part is to get people in the step with the program. Engineering Management, march, 2004.

HYER, N; WEMMERLÖV, U. Getting Cells in Place. Manufacturing Engineering, Mar p.89-97, 2003.

KANNAN, V. Cellular manufacturing using virtual cells. International Journal of Operations and Production Management, v 16, n 5, 1996.

cross ${ }^{\text {ref }}$

KUMAR, C.; CHANDRASEKHARAN, M. Grouping efficacy: a quantitative criterion for goodness of block diagonal forms of binary matrices in group technology. International Journal of Production Research, vol 28, pg. 233-243, 1990.

cross ${ }^{\text {ref }}$

LOIOLA, E.; NERIS, J. S.; TEIXEIRA, J. A. Difusão de células de manufatura no Brasil. In: Anais VIII Simpósio de Administração da Produção, Logística e Operações Internacionais (SIMPOI), FGV-EAESP, São Paulo, 2005. 
LORINI, F. Tecnologia de Grupo e Organização da Manufatura. Florianópolis: Ed. da UFSC, 1993.

MILTENBURG, J.; ZHANG, W. A comparative evaluation of nine well known algorithms for solving the cell formation problem in group technology. Journal of Operations Management, Vol. 10, pg 44-72, 1991.

cross ${ }^{\text {ref }}$

MONDEN, Y.. Toyota production system: practical approach to production management. Norcross: Industrial Engineering and Management Press, 1983.

MORRIS, J.S.;TERSIN, R.T. A simulation analysis of factors influencing the attractiveness of group technology cellular layouts. Management Science, vol 36, n. 12, pg 1567-78, 1990.

cross ref

MORRIS, J.S.;TERSIN, R.T. A simulation comparison of process and cellular layouts in a dual resource constrained environment. Computers and Industrial Engineering, vol 26, n 4, pg 733-41, 1994.

cross ${ }^{\text {ref }}$

NAIR, G.; NARENDRAN, T. Grouping index: a new quantitative criterion for goodness of block diagonal forms in group technology. International Journal of Production Research, vol 34, pg. 2767-2782, 1996.

cross ${ }^{\text {ref }}$

NG, S. M. Worst-case analysis of na algorithm for cellular manufacturing, European Journal of Operational Research, vol 69, n 2, pg 384-398, 1993

cross ref

SANTOS, A.; MOSER, L.; TOOKEY, J.E. Applying the Concept of Mobile Cell Manufacturing on the Drywall Process. Proceedings IGLC-10, 2002, Gramado, Brazil.

SARKER, B. R.; KHAN, M. A comparison of existing grouping efficiency measures and a new weighteed grouping efficincy measure. Institute of Industrial Engineering, vol. 33, pg. 11-27, 2001.

SHAMBU, G.; SURESH, N. C.; PEGELS, C. C. Performance evaluation of cellular manufacturing systems: a taxanomy and review research. International Journal of Operations and Production Management, vol. 16, n. 8, 1996.

cross ref

SHATER, S.; MEREDITH J.; MARSH, R. A taxonomy for alternative equipment groupings in bathc enviroments. Omega: The International Journal of Management Science, vol. 24, no. 4, 361-376, 1995.

SILVEIRA, G. J. C. Uma Metodologia de implantação da manufatura celular. Dissertação de Mestrado PPGEP/UFRGS, Porto Alegre, 1994.

SLACK, N; CHAMBERS, S; JOHNSTON, R. Administração da Produção. $2^{\circ}$ ed. São Paulo, ed. Atlas, 2002.

SURESH, N. C. Partitioning work centers for group technology: analytical-extension and shop level simulation investigation. Decision Science, vol. 23, no 2, 1992.

cross'

SURESH, N. C. The performance of hibrid group technology systems. In: Proccedings of the National Decision Science Institute, Miami, 1991.

SUZAKI, K. The new manufacturing challenge. New York: Free Press, 1987.

WEMMERLÖV, U; HYER, N Cellular manufacturing in the US industry: a survey of users. International Journal of Production Research, v 27, n 9, 1989.

WEMMERLOV, U; JOHNSON, D.J. Cellular manufacturing at 46 users plants: implementation experiences and performance improuvements. International Journal of Production Research, v 35, n 1, pg 29-49,1997. 
ZAWISLAK, P; MARODIN, G; GERBER, C. A Produção Enxuta Aplicada ao McDonald's. In: Anais VII Simpósio de Administração da Produção, Logística e Operações Internacionais (SIMPOI), FGV-EAESP, São Paulo, 2003. v.1

\section{Prof. Giuliano Marodin}

Universidade Federal do Rio Grande do Sul

Escola de Administração (EA/UFRGS) e Programa de Pós-Graduação em Engenharia de Produção (PPGEP / UFRGS)

Função ou cargo ocupado: Professor

Av. Guaiba, 3040, Bairro assunção, Porto Alegre, Brasil, CEP 91.900-420

Telefones: 32671677,99725294

e-mail:zmarodin@terra.com.br

\section{Prof. Dr. Tarcísio Abreu Saurin}

Universidade Federal do Rio Grande do Sul

Programa de Pós-Graduação em Engenharia de Produção (PPGEP / UFRGS)

Função ou cargo ocupado: Professor

Av. Osvaldo Aranha, 99 , $5^{\circ}$ andar, Centro, Porto Alegre, Brasil, CEP 90.040-020

Telefones: 33083948

e-mail:saurin@ufrgs.br

Recebido para publicação em: 13/08/07

Aceito para publicação em: 31/08/07 